\title{
Breeding Aspect for Improvement in Chrysanthemum: A Review
}

\author{
R. D. Baghele* \\ Department of Vegetable, Horticulture Research Scheme, Vasantrao Naik Marathwada Krishi \\ Vidyapeeth, Parbhani, M.S.-431402, India \\ *Corresponding author
}

\section{A B S T R A C T}

Chrysanthemum (Dendranthema grandiflora Tzvelve syn. Chrysanthemum morifolium Ramat.) is one of the most important flowering crop in the world. Flowers are highly prized for its varied color, form, size, shape and use. Developing Chrysanthemum cultivars with novel characteristic for its different

\section{Keywords}

Breeding,

Chrysanthemum,

mutation,

floriculture, x-ray

Article Info

Accepted:

12 April 2021

Available Online:

10 May 2021 flower color, shape, size, flowering time, postharvest quality tolerance for biotic and abiotic stress. In recent years, researchers have used various conventional and nonconventional breeding techniques to understand the classification studies, correlation and association both at morphological and molecular level, including transgenic technology, genome editing, and marker-assisted selection (MAS) with the wild relatives for introducing various ornamental traits from wild types to cultivated varieties. Moreover, the recent extensive advances in high-throughput technologies, especially genomics, transcriptomics, proteomics, metabolomics, and microbiomics, which are collectively referred to as omics platforms, have led to the collection of substantial amounts of data. Major traits which are targeted through biotechnological approaches includes development of novel flower colours, altered flower and plant morphology, insect-pest and disease resistance and enhanced postharvest attributes. This review summarizes the recent achievements in conventional and modern molecular breeding methods and emerging technologies for improvement in chrysanthemum for floriculture point of view.

\section{Introduction}

Chrysanthemum (Chrysanthemum morifolium Ramat.) belongs to the Asteraceae family. It is one of the most versatile, economically important and internationally recognized floriculture crop. Chrysanthemum has a long history of cultivation; it was first cultivated in
China as a herb in approximately the $15^{\text {th }}$ century BC and was then successively introduced to Japan, Europe, and the United States (Andorson, 2006). Maximum diversity of chrysanthemum is scattered in eastern parts of the world hence also recognized as 'Queen of East', 'Glory of East' or 'Autumn Queen'. Fukai et al., (1995) mention that 
Florists Chrysanthemums $(2 \mathrm{n}=54)$ originated by crossing and doubling between Chrysanthemum zawadskii var latilobum (Maxim.) kitamura $(2 \mathrm{n}=18)$ Chrysanthemum indicum var. Procumbense (Lour.) Kitamura $(2 n=36)$. Cultivated Chrysanthemum is a complex hexaploid that also exhibits aneuploidy, in which chromosome numbers vary from 47 to 67 (Dowrick, 1953). However, a chromosome number of 54 is the most frequent and stable conformation $(2 \mathrm{n}=6 \mathrm{x}=$ 54) (Roxas et al., 1995). The genus chrysanthemum comprises of 100 to 200 species which varies in their morphological attributes like growing habit, form and colour. The cluster analysis of ISSR-PCR for 86 plants of chrysanthemum revealed that Chrysanthemum vestitum is closest to medicinal and large flowered chrysanthemum in genetic distance and the evolution of chrysanthemum may be mainly in one way that is from wild chrysanthemum to medicinal chrysanthemum to ornamental Chrysanthemum (Zhou, 2009).

The market demands for chrysanthemum increase annually, forcing scientists and breeders to create new cultivars with novel appearances and improved stress tolerance and quality attributes. Conventional breeding approaches, including crossbreeding and mutation breeding, are the most common approaches used to develop new Chrysanthemum cultivars. Although, in classical approaches, breeders mainly use phenotypes to select superior progeny or mutants, a process that is often laborious and ineffective, especially for traits with significant genotype $\times$ environment $(\mathrm{G} \times \mathrm{E})$ interactions (Ibitoye and Akin, 2011). In recent years, transgenic molecular breeding has been extensively employed by introducing foreign genes into Chrysanthemum using Agrobacterium-mediated transformation and biolistic transformation and has led to considerable progress in horticultural character improvement. Due to the rapid development of DNA-based molecular marker techniques offers plant breeders a new opportunity to employ molecular marker-assisted selection (MAS) in breeding, which allows the indirect selection of target traits without regard to environmental factors or plant growth phases and shows great potential to increase the effectiveness of plant breeding (Das et al., 2017). With the advent and improvement of next generation sequencing (NGS) technology has accelerated the generation of multiomic data at the DNA, RNA, protein, and metabolite levels at an unprecedented rate, leading to a new era of big biological data (Choi, 2019).

In this review summarizes and focus on recent advances and technologies in chrysanthemum for further breeding programs.

\section{Conventional breeding Crossbreeding}

Chrysanthemum is a highly heterozygous plant and the variability in habit, height, vigour, period and quality of bloom, colour, size and shape of flowers, that shows inbreeding depression and self-incompatibility; as a result, conventional crossbreeding is a powerful method for developing modern chrysanthemum cultivars. Crossbreeding is simple and effective, and the F1 progeny derived from two parents with contrasting target traits generally exhibit a wide phenotypic variation in Chrysanthemum. Still, there are several factors that must be taken into consideration when crossbreeding Chrysanthemum, such as the fertility of a certain cross combination, qualitative analysis of the target traits, and superior hybrid progeny selection. New varieties are developed through conscious/selective artificial cross-pollination. This classical breeding uses deliberate interbreeding (crossing) of closely or distantly related individuals to produce new varieties with 
desirable properties. Plants are crossbred to introduce traits/genes from one variety or line into a new genetic background.

Interspecific and intergeneric hybridization have efficiently been used with the aid of embryo rescue techniques such as embryo and ovule culture to breed novel agronomic traits and to overcome incompatibility (Watanabe, 1977). Intergeneric hybrids between Chrysanthemum morifolium Nannongxiaoli and Artemisia vulgaris Variegata showed enhanced resistance against both aphids and alternaria leaf spot using ovule rescue technique as the hybrids inherited the flower quality of Nannongxiaoli' and favorable resistances to aphids and alternaria leaf spot from Variegata (Zhu et al., 2014). The inheritance of branching traits identified in different cultivars of Chrysanthemum revealed that two cross combinations both had cultivar Fukashi as a parent exhibited branching traits as highly heritable (Yang et al., 2015). Sun et al., (2010) reported that, crossed between the Chrysanthemum grandiflorum Yuhuaxingchen (excellent ornamental cultivar with low drought tolerance) with $C$. indicum having (drought tolerant) and six true hybrids, with that the improved drought tolerance were obtained.

\section{Mutation breeding}

Mutation breeding is a useful strategy in vegetatively propagated ornamental plants that has been widely exploited to modify one or a few traits in outstanding cultivars. Normally, mutations occur spontaneously, although they can be induced by physical and chemical methods. The mutation technique has successfully produced a large number of new chrysanthemum varieties that have been commercialized. Chrysanthemum when exposed to the effect of mutagen, most often the colour of the inflorescence changes which determines the decorative value of cultivars. Various chrysanthemum cultivars with novel traits, especially new flower colors and shapes, have been produced by $\mathrm{X}$-ray radiation, gamma radiation, and ionbeam irradiation. In present, microwave radiation, which is a form of electromagnetic radiation, has been used to induce genetic and phenotypic variations (novel flower shape and color, increased inflorescence diameter, and prolongation of bud coloration) in chrysanthemum (Miler and Kulus, 2018). The advantage of mutation breeding is that the high heterozygosity of chrysanthemum can increase the apparent mutation rate and produce many excellent mutation types in a short period of time. Even so, the primary limitations of this type of breeding are that mutations occur unpredictably throughout the genome, and often, only a single change is produced.

Induction of mutation not only used for the improvement of flower quality parameters but also agronomic traits e.g. salt tolerance (Hossain et al., 2006). Lema-Rumińska and Zalewska, (2005) obtained, from violet pink original cultivar Richmond, containing anthocyanins, mutants in which there was identified the presence of carotenoids or no anthocyanins at all in ligulate florets. The ionization irradiation can result in a partial or complete inactivation of the genes encoding the enzymes of pathway for the biosynthesis of anthocyanins. The mutations of that type which concern single genes result in the accumulation of intermediate compounds which leads to change in colour. Quantitative and qualitative changes in the content of pigments in inflorescences of the cultivars were obtained by the induction of mutagenic gamma radiation.

\section{Molecular breeding Transgenic breeding}

Transgenic technology can be used to transfer genes to a host plant from any source and to 
repress or enhance gene expression in a programmable manner. Compared with conventional breeding strategies, the transgenic method possesses greater prospective potential for producing innovative phenotypes. Cheng et al., (2013) reviewed that transgenic technology has become an important for breeding in new chrysanthemum cultivars and has led to great achievements related to floral attributes, plant architecture, postharvest, flower longevity, biotic and abiotic stress tolerance. Transgenic ornamental plants are becoming beneficial for both growers and consumers due to their novel appearances and enhanced stress tolerance without presenting food safety concerns, in contrast to fruits and vegetables. Ledger et al., (1991) first tried to generate transgenic chrysanthemum (Dendranthema indicum Korean) using Agrobacterium strain LBA4404, but reported to have very low transformation frequency $(1.7 \%)$. Hence, this review describes only the most recent reports of several useful traits that have been introduced into chrysanthemum.

\section{Abiotic and biotic stress tolerance}

The industrialization of Chrysanthemum is limited by several abiotic and biotic stresses, including drought, salt, extreme temperature, and insect pests. With this, the development of new cultivars with increased tolerance has always been a goal of breeders. Ling (2018) suggests that DgWRKY2 could be used as a reserve gene for salt-tolerant plant breeding. Lower accumulation of reactive oxygen species (ROS) and higher enzymatic activity of peroxidase, superoxide dismutase and catalase in CmWRKY10 over expressed lines than that of WT demonstrates its role in drought tolerance. The CmWRKY10 works as a positive regulator in drought stress by regulating stress-related genes (M. Abuzar Jaffar et al., 2016). Over expression of the $C$. lavandulifolium gene ClCBF1 in the chrysanthemum cv. 'White Snow' improved its salt and drought tolerance. The transgenic Cm- BBX24 plants also responded to salt and drought stresses, possibly due to changes in gibberellic acid (GA) biosynthesis.

\section{Flowering time}

Flowering time is the main determinant of successful commercial plants, and the development of early flowering cultivars helps meet consumers' needs by allowing plants to bear more flowers or be produced in sufficient numbers for the celebration of particular festivals. Yang et al., (2014) created transgenic RNA interference (RNAi)-suppressed chrysanthemum plants that flowered $\sim 20 \mathrm{~d}$ earlier than Cm-BBX24overexpressing and wild plants under longday conditions. Wei et al., (2017) showed that age-dependent regulation of SPL TFs by miR156 influences flowering by controlling CmNF-YB8 expression in chrysanthemum. More recently, overexpression of CmERF110 in transgenic Arabidopsis accelerated flowering by $\sim 7 \mathrm{~d}$ compared with non-transgenic plants (Xing et al., 2019).

\section{Flower color}

Flower color is a major objective in Chrysantemum breeding due to its strong influence on consumer choice. By the several internal and external factors, such as vacuolar $\mathrm{pH}$, metal ions, and coexisting colorless compounds, also affect the formation of different colour pattern in flowers. Seita et al., 2006) reported that diverse flower colors have been observed in chrysanthemum during its long history of cultivation, violet and blue colors are lacking due to a deficiency in flavonoid 3'5'-hydroxylase (F3'5'H) activity. Ohmiya et al., (2006) reported that suppression of $\mathrm{CmCCD} 4 \mathrm{a}$ expression by RNAi in white-flowered 
chrysanthemums produced yellow-flowered transformants. In other experiments (Yoshioka et al., 2010) involving crosses between white- and yellow-flowered chrysanthemums indicated the presence of CmCCD4a led to the development of white ray petals. $\mathrm{F}^{\prime} 5^{\prime} \mathrm{H}$ is a key enzyme for delphinidin biosynthesis in most blue-hued flowers. In the past, transgenic chrysanthemums with a violet ray-petal color were produced by expressing a heterologous $\mathrm{F}^{\prime}{ }^{\prime} 5^{\prime} \mathrm{H}$ gene under the control of ray-petal-specific promoters (Noda et al., 2013).

\section{Genome editing}

Recently, genome editing has been used as a vital tool for functional genomics and biotechnology research and has become available as a precision-breeding approach for modifying traits in plant species. Genome-editing techniques theoretically allow researchers to introduce mutations into any targeted genomic sequence, and mutations in genome-edited plants are heritable. Now a days, few reports have demonstrated successfully on genome editing for flower color in ornamental plants by using the CRISPR/Cas9 method. Kishi- Kaboshi et al., (2017) first attempted to use multicopy transgenes instead of endogenous genes as targets for genome editing in chrysanthemum.

The resultant transgenic chrysanthemum possessed over five copies of the yellowishgreen fluorescent protein gene (CpYGFP) from Chiridius poppei, allowing the visualization of gene editing progress. Two single-guide RNAs (sgRNAs) were used to target different positions in the CpYGFP gene, and transgenic lines with mutated CpYGFP genes were acquired, showing that axillary buds and callus regeneration contribute to mutation.

\section{Linkage maps and QTL mapping}

A linkage map provides a basis for the identification of genomic regions related to traits of interest and the necessary infrastructure for MAS breeding.

Quantitative trait locus (QTL) mapping is a conventional tool for identifying the genes that control a trait, and it is useful for genome-wide scanning for QTL detection based on a linkage map in plants. Generally, linkage maps in chrysanthemum are most efficiently constructed according to the 'double pseudotestcross' mapping strategy in an F1 population. Zhang et al., (2019), produce first preliminary linkage map of chrysanthemum from a bi-parental cross using a combination of RAPD, AFLP, and inter simple sequence repeat (ISSR) markers.

In some studies it is identified that molecular markers associated with the selected characters, preliminarily screened excellent progeny, and provided important basic genetic resources for chrysanthemum breeding programs.

\section{Omics technologies Genomics}

Genomic research has a vast capacity to accelerate the breeding process and presents applications for genetic improvement such as MAS and gene pyramiding. The genomic information of cultivated chrysanthemum has not been reported, mainly due to its unknown origin, heterozygosity, extremely large genome size $(9.4 \mathrm{~Gb}$, ttp://www.etnobiofic.cat/gsad_v2/), and high repeat content. Early on, bacterial artificial chromosome (BAC) libraries were widely used for whole-genome sequencing (WGS). However, this approach consisted of a laborious process of constructing a physical map composed of many BAC clones (Das et al., 2017). 
Table.1 List of chrysanthemum cultivars released by different institutes in India

\begin{tabular}{|c|c|c|c|}
\hline Institutes & Hybridization & Selection & Mutation \\
\hline $\begin{array}{l}\text { NBRI, } \\
\text { Lucknow }\end{array}$ & $\begin{array}{l}\text { Ajay, Appu, Apsara, Apurva, Apurva } \\
\text { Singar, Arun Kumar, Arun Singar, } \\
\text { Bindiya, Birbal Sahani, Dhawal, Diana, } \\
\text { Gauri, Gulal, Guldasta, Haldighat,, } \\
\text { Hemant Singar, Himanshu, Jaya, Jayanti, } \\
\text { Jubilee, Jwala, Jyoti, Jyotsna, Kargil 99, } \\
\text { Kaumudi, Kiran, Kirti, Kundan, Lal Kila, } \\
\text { Lalima, Lalpari, Lilith, Maghi, May-Day, } \\
\text { Mayur, Meghdoot, Mini-Queen, Mohini, } \\
\text { Mother-Teresa, NBRI Pushpangadan, } \\
\text { NBRI Khoshoo, NBRI Kaul, NBRI } \\
\text { Himanshu, NBRI Little Orange, NBRI } \\
\text { Little Hemant, NBRI Little Kusum, NBRI } \\
\text { Little Pink, NBRI Yellow Bud Sport, } \\
\text { Neelima, Niharika, Nirmal, Pancho, Peet } \\
\text { Singar, Phuhar, Priya, Prof. Harris, Puja, } \\
\text { Ragini, Rangoli, Sadbhavna, Shant, } \\
\text { Ratna, Sharda, Sharad Kanti,‘ Sharad }\end{array}$ & & $\begin{array}{l}\text { Sharad Mukta, } \\
\text { Sharad Sandhya, } \\
\text { Sharad Shobha, } \\
\text { Sharad Singar, } \\
\text { Shizuka, Shyamal, } \\
\text { Suhag Singar, } \\
\text { Sujata, Suneel, } \\
\text { Sunayana, Suparna, } \\
\text { Surekha Yellow, } \\
\text { Surya, Swarn } \\
\text { Singar, Sweta } \\
\text { Singar, Tushar, } \\
\text { Vandana, } \\
\text { Vasantika, Vijay, } \\
\text { Vijay Kiran, Vinaya, } \\
\text { White Charm, } \\
\text { White Profile, Y2K, } \\
\text { Yellow Charm, }\end{array}$ \\
\hline $\begin{array}{l}\text { IARI, New } \\
\text { Delhi }\end{array}$ & & $\begin{array}{c}\text { Pusa Aditya, } \\
\text { Pusa Sona, Pusa } \\
\text { Anmol, Pusa } \\
\text { Chitraksha, Pusa } \\
\text { Guldasta, Pusa }\end{array}$ & $\begin{array}{l}\text { Pusa Arunodya, } \\
\text { Pusa Kesari }\end{array}$ \\
\hline $\begin{array}{c}\text { IIHR, } \\
\text { Bengalore }\end{array}$ & $\begin{array}{l}\text { Arka Ganga, Arka Pink Star, Arka Ravi } \\
\text { Arka Swarna, Chandrakant, Chandrika, } \\
\text { Indira, Kirti, Nilima, Pankaj, Rakhee, } \\
\text { Ravikiran, Red Gold, Yellow Star, Yellow } \\
\text { Gold, Usha Kiran }\end{array}$ & & \\
\hline \multirow[t]{2}{*}{$\begin{array}{c}\text { PAU, } \\
\text { Ludhiana }\end{array}$} & $\begin{array}{l}\text { Anmol, Baggi, Gul-E-Sahir, Royal Purple, } \\
\text { Yellow Delight, Autumn Joy, Garden }\end{array}$ & & \\
\hline & $\begin{array}{l}\text { Beauty, Winter Queen, Punjab Gold, } \\
\text { Punjab Shyamli }\end{array}$ & & \\
\hline YSP, Nauni & & Solan Shringar & \\
\hline $\begin{array}{c}\text { TNAU, } \\
\text { Coimbatore }\end{array}$ & $\mathrm{CO} 1, \mathrm{CO} 2, \mathrm{MDU}$ & & \\
\hline
\end{tabular}

(Sangeeta et al., 2019) 
Table.2 List of mutant variety released by different countries.

\begin{tabular}{|c|c|c|}
\hline Countries & & Varieties released \\
\hline Belgium & 7 & $\begin{array}{l}\text { Marconi, Copper Marconi, Red Marconi, Dark Red Marconi, } \\
\text { Torino, Dark Torino, Yellow Torino }\end{array}$ \\
\hline Brazil & 3 & Repin Rosa, Ingrid, Cristiane \\
\hline China & 19 & Xishihanxiao, Chuntao, Yingsidai, Mantianxin, Zixia \\
\hline India & 49 & $\begin{array}{l}\text { Agnisikha, Navneet, Subama, Sonali, Surekha Yellow, Sharad Har, } \\
\text { Navneet Yellow, Jugnu, Batik, Raktima, Kesar, Lalima Tubular }\end{array}$ \\
\hline Japan & 56 & $\begin{array}{l}\text { Amazon, Araddin, Baiogiku Rainbow orange, Baiogiku Rainbow } \\
\text { Peach, Baiogiku Rainbow Pink, Baiogiku Rainbow Red, Baiogiku } \\
\text { Rainbow White, Baiogiku Rainbow Yellow, Yellow Prism etc }\end{array}$ \\
\hline The Netherlands & 80 & $\begin{array}{l}\text { Amber Boston, Apricot Impala, Blue Star, Blue Winner, Bronze } \\
\text { Star, Dark Milos, Yellow Winner, Yellow Westland, Yellow Clingo }\end{array}$ \\
\hline Germany & 34 & $\begin{array}{l}\text { Izetka Filmstar Bronze, Izetka Herbstgold, Izetka Kopenicker } \\
\text { Barbarossa Rotstern, Izetka Marienhain Cremeweiss etc }\end{array}$ \\
\hline Poland & 6 & Lady Amber, Lady Bronze, Lady Salmon etc \\
\hline Russian & 17 & Radii, Saputnik, Selena, Sointse, Saturn etc \\
\hline Vietnam & 3 & VCM 1, VCM 2, VCM 3 \\
\hline Korean Republic & 2 & ARTI Purple, ARTI Queen \\
\hline Thailand & 1 & Golden Cremon \\
\hline
\end{tabular}

(Sangeeta et al., 2019)

Table.3 Some of the genetic transformation studies in chrysanthemum

\begin{tabular}{|l|c|c|}
\hline \multicolumn{1}{|c|}{ Species/Cultivars } & Foreign genes & References \\
\hline Dendranthema grandiflora & NPT II, GUS & (Van Wordragen et al., 1991) \\
\hline Dendranthema grandiflora cv. 'Yellow Spider' & GUS, NPT II & (Pavingerova et al., 1994) \\
\hline Dendranthema grandiflora cv. 'Kitamura' & NPT II, GUS & (Seiichi et al., 1995) \\
\hline $\begin{array}{l}\text { Dendranthema grandiflora cvs. 'Polaris', 'Hekla', } \\
\text { 'Iridon' }\end{array}$ & GUS, NPT II & (Sherman et al., 1998) \\
\hline Dendranthema grandiflora cv. 'Peach Margaret' & NPT II & (Boase et al., 1998) \\
\hline Dendranthema grandiflora & GUS & (Seo et al., 2003) \\
\hline
\end{tabular}

The expansion of gene families by duplication events may lead directly to variation in the ornamental and medicinal characteristics of chrysanthemum. The genome assembly of $C$. seticuspe using the Illumina sequencing platform produced $2.72 \mathrm{~Gb}$ of sequences consisting of 354,212 scaffolds with an N50 length of $44.7 \mathrm{~kb}$, covering $\sim 89.0 \%$ of the estimated genome size. SNP identification and annotation performed by mapping the transcriptome data of six chrysanthemum varieties onto the $C$. seticuspe genome demonstrated that the $C$. seticuspe genome is applicable to genetic analysis in cultivated chrysanthemums (Jiangshuo et al., 2019).

\section{Plant growth and development}

Plant growth and development is a complicated hierarchical system that is dynamically controlled by a network composed of various genes. Flowering is a 
complex developmental process in plants during which morphological and physiological changes affecting several external and internal factors occur (Amasino, 2010). Further studies showed that TCP4 and TCP9 may function as positive regulators of chrysanthemum petal growth. Novel flower shape is of great importance for marketing in ornamental plants. A comparative transcriptome analysis between the florets and leaves revealed several key DEGs involved in flower development, flower organ differentiation, and anthocyanin biosynthesis (Liu et al., 2015).

\section{Stress resistance}

Mining crucial genetic resources controlling resistance characters will greatly contribute to breeding programs. Transcriptomesequencing technology has been widely used for the identification of major regulatory genes and gene networks controlling responses to several abiotic stresses (i.e., drought, salt, cold, heat, and waterlogging).

Chrysanthemums are easily attacked by aphids throughout the growing season, seriously affecting their growth and ornamental value. MicroRNAs (miRNAs), which are $\sim 22 \mathrm{nt}$ in size, are the most abundant class of endogenous noncoding small RNAs (smRNAs) in plants and play important roles in plant biological processes (Sun, 2012). Designing a rational set of experiments to investigate common genes or pathway responses to multiple stresses would provide breeders with an opportunity to improve the synthetic resistance of chrysanthemum by developing gene-specific molecular markers or pursuing transgenic breeding. The responses of plants to stresses and the acquisition of stress resistance are regulated by a complex system of interacting signals and are susceptible to some environmental factors.

\section{Proteomics}

Ornamental chrysanthemums are traditionally cultivated by vegetative stem cutting, after which regeneration occurs via adventitious roots; therefore, the investigation of the molecular mechanisms underlying adventitious root formation is of particular significance in chrysanthemum breeding. Proteomic approaches have been successfully used in several sequenced plants, such as rice and Arabidopsis, to study diverse bioprocesses and environmental adaptations (Vanderschuren, et al., 2013). A comparative proteomic analysis of postharvest medicinal chrysanthemum flowers under normal or UV-B radiation conditions allowed the detection of 43 differentially accumulated protein spots, some of which were identified as participating in photosynthesis, respiration, and defense (Yao, et al., 2015).

\section{Prospects of chrysanthemum breeding}

With the rising demand for chrysanthemum, the development of new attractive cultivars with comprehensive resistance to various environmental stresses is urgently needed. Molecular and omics methods are expected to expedite the breeding process compared with conventional methods, which remain the mainstay of practical breeding programs for hexaploid chrysanthemum. Selecting suitable parent or populations with desired traits from the abundant germplasm resources of Chrysanthemum, which were materials used for genetic studies, it is the fundamental basis of breeding programs. The exploration of feasible methods for employing these new technologies is still in the initial stage for chrysanthemum. Despite the restrictions discussed in this article, the combination of modern breeding strategies with conventional methods would clearly be a superior approach for improving major horticultural characteristics, incorporating 
multiple characters into a single cultivar and expanding the usage of chrysanthemum in the floriculture industry.

It is concluded that, presently commercial floriculture being the most profitable business is expanding rapidly all over the world. Use of advanced science based techniques has given an impetus to the growth of this industry. An important driving force for the floriculture industry is the development of novel features in ornamentals. Chrysanthemum is one of the most important floricultural crops in the cut flower, flowering pot plants and herbaceous perennial markets of the world. Conventional breeding relies primarily on selection, using natural processes of sexual and asexual reproduction. This method has long become the base of development of a lot of cultivars. While some the advanced methods like mutation breeding and genetic engineering has played key role in the development of novel and desirable traits in plants. Mutation breeding has played tremendous role in the development of large number of cultivars. Breeding for novel color, such as rare blue colour, would be valuable for the flower industry and its consumers. Genetically modified crop plants are now grown over a very large area in several countries which is true for agriculture crops. In the Chrysanthemum the new varieties being produce for the commercialized among the farmers.

\section{References}

Anderson N. O. (2006). Flower Breeding and Genetics: Issues, Challenges and Opportunities for the 21st Century. (Springer Science and Business Media).

Amasino R. (2010). Seasonal and developmental timing of flowering. Plant J. 61: 1001-1013. Choi H. K. (2019). Translational genomics and multi-omics integrated approaches as a useful strategy for crop breeding. Genes Genom. 41: 133-146.

Cheng L., Wei Q., Imtiaz M., Gao J. and Hong B. (2013). Advances in application of transgenic breeding technology in the traits improvement of chrysanthemum. Acta Hortic. Sin. 40: $1813-1825$

Dowrick G. J. (1953). The chromosomes of Chrysanthemum, II: garden varieties. Heredity 7: 9- 72.

Das G., Patra J. K. and Baek K. H. (2017). Insight into MAS: a molecular tool for development of stress resistant and quality of rice through gene stacking. Front. Plant Sci. 8: 985.

Fukai S., Jong De and Rademaker W. (1995). Efficient genetic transformations of chrysanthemum (Dendranthema grandiflora Ramat) using stem segments. Breed. Sci. 45: 179- 184.

Hossain Z., Mandal A. K. A, Datta S. K. and Biswas A. K. (2006). Development of $\mathrm{NaCl}$ - tolerant strain in Chrysanthemum morifolium Ramat. through in vitro mutagenesis. Plant Biology 8: 450-461.

Ibitoye D. and Akin-Idowu P. (2011). Markerassisted-selection (MAS): a fast track to increase genetic gain in horticultural crop breeding. Afr. J. Biotechnol. 10: 11333-11339.

Kishi-Kaboshi M., Aida R. and Sasaki K. (2017). Generation of gene-edited Chrysanthemum morifolium using multicopy transgenes as targets and markers. Plant Cell Physiol. 58: 216226 Lema-Rumińska J. and Zalewska M. (2005). Changes in flower colour among Lady Group of Chrysanthemum $\times$ grandiflorum Ramat.) Kitam, as a result of mutation breeding. Fol. Hortic. Ann.17: 61-72. 
Ledger S. E, Deroles S. C, and Given N. K. (1991). Regeneration and Agrobacterium-mediated transformation of chrysanthemum. Plant Cell Rep. 10:195-199.

Ling He, Yin-Huan Wu, Qian Zhao, Bei Wang, Qing-Lin Liu and Lei Zhang (2018). Chrysanthemum DgWRKY2 gene enhances tolerance to salt stress in transgenic chrysanthemum. Int. J. Mol. Sci. 19: 1-17.

Liu H. et al., (2015). Whole-transcriptome analysis of differentially expressed genes in the vegetative buds, floral buds and buds of Chrysanthemum morifolium. PLoS ONE 10: e0128009. Jiangshuo Su, Jiafu Jiang, Fei Zhang, Ye Liu, Lian Ding, Sumei Chen and Fadi Chen (2019). Current achievements and future prospects in the genetic breeding of chrysanthemum: a review. Horti. Res. 6 (109):1-19

Miler N. and Kulus D. (2018). Microwave treatment can induce chrysanthemum phenotypic and genetic changes. Sci. Hortic. 227: 223-233.

Muhammad Abuzar Jaffar, Aiping Song, Muhammad Faheem, Sumei Chen, Jiafu Jiang, Chen Liu, Qingqing Fan and Fadi Chen (2016). Involvement of CmWRKY10 in drought tolerance of Chrysanthemum through the abasignaling pathway. Int. J. Mol. Sci. 17: 1-14.

Noda N. et al., (2013). Genetic engineering of novel bluer-colored chrysanthemums produced by accumulation of delphinidin-based anthocyanins. Plant Cell Physiol. 54: 1684-1695

Ohmiya A., Kishimoto S., Aida R., Yoshioka S. and Sumitomo K. (2006). Carotenoid cleavage dioxygenase (CmCCD4a) contributes to white color formation in chrysanthemum petals. Plant Physiol. 142:1193-1201
Roxas N. J., Tashiro Y., Miyazaki S., Isshiki S. and Takeshita A. (1995). Meiosis and pollen fertility in Higo chrysanthemum (Dendranthema $\times$ grandiflorum (Ramat.) Kitam. J. Jpn. Soc. Hortic. Sci. 64: 161-168.

Sangeeta Kumari, Dhiman S. R. and Gupta Y. C. (2019). Advances in Breeding of Chrysanthemum: A Review. Int. J. Curr. Microbiol. App. Sci. 8(8): 16311643.

Sun C. Q., Chen F. D., Teng N. J., Liu J. L., Fang W. M. and Hou X. L. (2010). Interspecific hybrids between Chrysanthemum grandiflorum (Ramat.) Kitamura and Chrysanthemum indicum (L.) Des Moul and their drought tolerance evaluation. Euphytica 174:51-60.

Seitz C. et al., (2006). Cloning, functional identification and sequence analysis of flavonoid 3'- hydroxylase and flavonoid 3'5'-hydroxylase cDNAs reveals independent evolution of flavonoid 3',5'-hydroxylase in the Asteraceae family. Plant Mol. Biol. 61: 365-381.

Sun G. (2012). MicroRNAs and their diverse functions in plants. Plant Mol. Biol. 80: 17-36. Vanderschuren H., Lentz E., Zainuddin I. and Gruissem W. (2013). Proteomics of model and crop plant species: status, current limitations and strategic advances for crop improvement. J. Proteom. 93: 519.

Wei Q. et al., (2017). Control of chrysanthemum flowering through integration with an aging pathway. Nat. Commun. 8: 829.

Watanabe K. (1977). Successful ovary culture and production of F1 hybrids and androgenic haploids in Japanese Chrysanthemum species. J. Hered. 68:317-320.

Xing X. et al., (2019). The constitutive 
expression of a chrysanthemum ERF transcription factor influences flowering time in Arabidopsis thaliana. Mol. Biotechnol. 61: 20-31

Yang Y., Wen C., Nan M. and Zhao L. (2015). Heterosis and genetic analysis of branching in cut-flower chrysanthemums. Euphytica 205:915925.

Yang, Y. et al., (2014). A zinc finger protein regulates flowering time and abiotic stress tolerance in chrysanthemum by modulating gibberellin biosynthesis. Plant Cell 26: 2038-2054

Yoshioka S, Sumitomo K, Fujita Y, Yamagata A, Onozaki T, Shibata M and Ohmiya A. (2010). Significance of $\mathrm{CmCCD} 4 \mathrm{a}$ orthologs in apetalous wild chrysanthemum species, responsible for white coloration of ray petals. Euphytica 171: 295-300.

Yao X. et al., (2015). Biochemical traits and proteomic changes in postharvest flowers of medicinal chrysanthemum exposed to enhanced UV-B radiation. J. Photochem. Photobiol. 149: 272279.

Zhang F., Chen S., Chen F., Fang W. and Li F. (2019). A preliminary genetic linkage map of chrysanthemum (Chrysanthemum morifolium) cultivars using RAPD, ISSR and AFLP markers. Sci. Hortic. 125: 422-428.

Zhou J. (2009). Studies on the problem of origin of Chinese garden chrysanthemum. Ph.D Thesis, Beijing Forestry University, Beijing, China.

Zhu W. Y., Zhang F., Chen S. M., Xu L. L., Wang L. and Wang H. B. (2014). Intergeneric hybrids between Chrysanthemum morifolium Nannongxiaoli' and Artemisia vulgaris Variegata show enhanced resistance against both aphids and alternaria leaf spot. Euphytica 197: 399-408.

\section{How to cite this article:}

Baghele, R. D. 2021. Breeding Aspect for Improvement in Chrysanthemum: A Review. Int.J.Curr.Microbiol.App.Sci. 10(05): 101-111. doi: https://doi.org/10.20546/ijcmas.2021.1005.015 